\title{
PROCESSOS DE SEPARAÇÃO E RECOLHA SELECTIVA DE RESÍDUOS NOS ORGANISMOS PÚBLICOS O CASO PORTUGUÊS
}

\author{
CÉSAR MADUREIRA ${ }^{1}$ \\ MARGARIDA QUINTELA MARTINS ${ }^{1}$ \\ Miguel Rodrigues ${ }^{1}$
}

\begin{abstract}
Resumo - O presente texto apresenta um estudo sobre os níveis de desenvolvimento de diferentes organismos da administração pública central portuguesa relativamente às práticas de separação e recolha selectiva de resíduos em contexto de trabalho, com vista a efectuar um diagnóstico que possa fundamentar medidas a tomar para incrementar boas práticas de recolha e separação selectiva de resíduos. Foi também tratada a questão da mudança de comportamentos de dirigentes e funcionários no que concerne à separação dos resíduos no local de trabalho.
\end{abstract}

Palavras-chave: Administração Pública, separação e recolha selectiva de resíduos, gestão ambiental, mudança comportamental.

\begin{abstract}
Selective waste separation and collection. The portuguese CASE. This paper addresses the issue of selective waste separation and collection practices in work environments by public administration organisations. It puts forth a diagnosis of the level of development attained in this area, with the aim of contributing to the debate on which measures should be taken in order to foster good practices in terms of selective waste separation and collection. The issue of behavioural change by both managers and subordinates is the object of a special focus.
\end{abstract}

Keywords: Public Administration, selective waste separation and collection, environmental management, behavioural change.

Résumé - TECHNIQUES DE SÉPARATION ET DE RAMASSAGE SÉLECTIF DES DÉCHETS DANS LES SERVICES PUBLICS. LE CAS PORTUGAIS. On présente une étude sur les divers niveaux de séparation et de recueil sélectif des déchets, pratiqués par plusieurs organismes de l'Administration Publique Centrale au Portugal. Cette étude peut servir à établir un diagnostique, qui permettra de déterminer les mesures à prendre pour améliorer les pratiques de ramassage sélectif des déchets. On s'est aussi intéressé aux

Recebido: 09/03/2009. Aceite: 07/01/2010

1 EMIC-INA (Equipa Multidisciplinar de Investigação e Consultoria do Instituto Nacional de Administração, I.P.).E-mail: cesar.madureira@ina.pt; margarida.martins@ina.pt; miguel.rodrigues@ ina.pt 
changements de comportement des dirigeants et des employés, par rapport au problème de la sélection des divers résidus sur le lieu de travail.

Mots-clés: Administration Publique, séparation et ramassage sélectif des déchets, gestion de l'environnement, changement de comportement.

\section{INTRODUÇÃO - PROBLEMÁTICA E OBJECTIVOS}

No contexto da globalização, em que se procura aprofundar o denominado desenvolvimento sustentável, as políticas de gestão ambiental e, consequentemente, de separação, recolha selectiva e reciclagem dos materiais utilizados, ocupam cada vez mais destaque. Pela dimensão física que ocupam no desenvolvimento dos estados, das sociedades e da educação e formação dos cidadãos, os governos e a administração pública, para além de serem importantes agentes de progresso económico e social, desempenham também papel relevante no que concerne à utilização de bens consumíveis. Daqui decorre que a administração pública portuguesa seja produtora de um volume não negligenciável de resíduos de diversa índole.

Desta forma, importa perceber o que está a ser feito ao nível da separação e recolha selectiva destes bens, no seu fim de vida enquanto resíduos, e o que poderia ser melhorado. O presente texto tem por objectivo verificar os níveis de desenvolvimento dos diferentes organismos da administração pública central portuguesa relativamente às práticas de separação e recolha selectiva de resíduos em contexto de trabalho, para efectuar um diagnóstico que sirva de base a uma reflexão sobre as medidas a tomar para incrementar boas práticas de recolha e separação selectiva de resíduos.

\section{MARCO TEÓRICO - SOCIEDADE DE CONSUMO E GESTÃO DE RESÍDUOS}

Numa sociedade em que o hedonismo ganha culturalmente um papel da maior relevância, o consumo passou a ser uma das chaves principais para a realização imediata das expectativas dos cidadãos. A utilização dos produtos adquiridos no mercado, nomeadamente os de carácter tecnológico, tem um tempo médio de duração cada vez mais curto. A publicidade trata, por seu turno, de criar necessidades, tantas vezes artificiais ou superficiais, nos consumidores (Aranha e Martins, 1993). Ramonet (2004) vai mesmo mais longe afirmando que "ao mesmo tempo veículo ideológico e técnica de persuasão, a publicidade sabe enfeitar-se com os melhores acessórios de sedução, mobilizando todos os recursos da estratégia do desejo sob todas as suas formas". Por outro lado, na sociedade de consumo, de acordo com as representações sociais dominantes, a não aquisição de certos bens e serviços pode revelar-se inibidora da obtenção de uma posição social, estatutária ou profissional mais desejada (Marcuse, 2001, Ramonet 2004). Segundo Portilho (2005), é fundamental estudar as circunstâncias em que será possível conjugar harmoniosamente o consumo, a sustentabilidade ambiental e a vida de todos os actores sociais que compõem a sociedade num determinado momento.

Se a preocupação e o consequente incremento do número e da profundidade das investigações que são feitas no estudo do consumo são fundamentais para percebermos a fundo este fenómeno, torna-se também imperativo estudar as suas consequências sociais 
e, sobretudo, ambientais. Daí ser determinante a definição rigorosa do conceito de gestão dos resíduos. De acordo com Tchobanoglous et al., (1993:7), a gestão dos resíduos pode ser definida como "a disciplina que estuda a geração, a separação, a recolha, o transporte, o processamento e a reutilização ou reciclagem dos resíduos, visando estabelecer princípios para a Saúde pública, a Economia, a Engenharia, a Conservação e o Ambiente, assim como promover a responsabilização nas atitudes públicas relativas a este fenómeno". Nesta perspectiva, a gestão dos resíduos deve envolver todas as abordagens, administrativas, financeiras, legais, técnicas e de planeamento que possam participar na construção de soluções para os problemas decorrentes da existência dos resíduos. Estas soluções devem ainda envolver relações interdisciplinares complexas que entrem em conta com outras variáveis, como sejam as de carácter demográfico, político, geográfico, sociológico e psicológico.

Do ponto de vista dos governos, no contexto da sociedade de consumo, os cidadãos têm tendencialmente vindo a ser encarados como agentes activos da gestão ambiental, sendo frequentemente interpelados no sentido de se mobilizarem para a separação, reutilização e reciclagem de materiais. No entanto, apesar de todas as idiossincrasias demográficas, geográficas, socio-económicas, políticas e educacionais que distinguem os diferentes grupos sociais, segundo Folz e Hazlett (1991), o sucesso dos programas de separação, de recolha selectiva e de reciclagem depende essencialmente das políticas para o ambiente, da forma como são escolhidas, seleccionadas e implementadas por governos e administrações.

\section{SEPARAÇÃO DE RESÍDUOS E MUDANÇA COMPORTAMENTAL}

Lewin (1965) é uma das referências incontornáveis no capítulo da teoria do processo de mudança. Segundo ele poderiam ser identificadas três fases ao longo de um processo de mudança: o descongelamento, a mudança e o recongelamento. Mais recentemente, Schein (1987), tentando desenvolver o conteúdo de cada uma das fases propostas por Lewin, postulou que o descongelamento deveria funcionar como um mecanismo de remoção ou de destruição de crenças, valores, atitudes e comportamentos partilhados e praticados pelos indivíduos até esse momento, através da apresentação de novos padrões e de novos estímulos comportamentais, susceptíveis de desafiarem a solidez dos anteriores.

Num processo de mudança cultural de fundo, e consequentemente de mentalidades dos funcionários no que concerne aos hábitos de separação de resíduos no local de trabalho (neste caso, nos organismos públicos), parece inequívoca a necessidade de intervenção dos dirigentes enquanto precursores da mudança e a instituição de novas regras susceptíveis de motivarem novas atitudes e comportamentos (Madureira, 2004).

Por outro lado, num contexto de mudança organizacional, a questão interpretativa é crucial. Os motivos indicados pelos dirigentes aos funcionários, como justificações para a mudança, e sobretudo a forma como estes são percepcionados e interpretados, são determinantes na definição da conduta de uma associação, ou ao contrário, de distanciamento relativamente às modificações introduzidas. A credibilidade é pois um elemento central na implicação dos indivíduos nos processos de mudança.

Se encararmos como desejável a criação de hábitos de separação, tendo em vista a reciclagem dos resíduos de forma continuada, então é saudável que esta se faça em 
associação com os novos comportamentos "ambientalmente responsáveis" dos dirigentes da administração pública que deverão ser continuados e visíveis dentro da organização.

Com efeito, para que possa ser efectiva a participação de todos os actores organizacionais em processos de mudança comportamental, no que concerne a separação e o tratamento dos resíduos, terá que estar alicerçada numa partilha de novos símbolos, novos códigos de linguagem e, fundamentalmente, de novas atitudes e comportamentos. Num processo deste tipo, motivação e comunicação são elementos nucleares.

Uma vez que as estruturas públicas têm ainda uma forma piramidal, com ordens, regulamentos e definição de práticas de conduta a serem emanadas do topo, para que possa haver partilha de uma nova linguagem relativamente à separação de resíduos na administração pública, ela deverá começar nas camadas dirigentes.

\section{SEPARAÇÃO, RECOLHA SELECTIVA E RECICLAGEM NOS ORGANISMOS PÚBLICOS}

Em 1992, a Conferência das Nações Unidas para o Meio Ambiente e o Desenvolvimento (CNUMAD), que ocorreu no Rio de Janeiro, marcou o início de uma nova era no que concerne à gestão ambiental. Com efeito, 190 estados discutiram a Agenda 21 Global, comprometendo-se a "pensar globalmente e a agir localmente" através da implementação de medidas para a promoção de acções visando a redução das desigualdades sociais, assim como a adopção de um modelo de desenvolvimento com bases ambientais mais sustentáveis.

Contudo, para que os estados possam levar a cabo tais pretensões, as administrações públicas dos diferentes países devem desempenhar um papel de agentes activos no processo de transformação das sociedades. Neste sentido, antes de porem em prática medidas que visem sensibilizar o cidadão comum para a questão da preservação do meio ambiente, estados e administrações deverão constituir-se como pioneiros na adopção de práticas de defesa activa do ambiente.

Em todo o mundo, bens tão diversos como consumíveis (papel, toners de impressoras), material informático (hardware), entre outros materiais, são utilizados em larga escala, não só pelo tecido empresarial privado mas também pelos serviços públicos. Desta forma, torna-se imprescindível que estes organismos obedeçam a estratégias de prevenção e reciclagem, assim como a programas de separação, recolha selectiva, reciclagem, ou reutilização dos materiais para poupar recursos naturais e de evitar poluição e desperdícios. Folz (2004) sugere mesmo que os organismos públicos, particularmente as autarquias, devem proceder a processos de benchmarking entre eles, com o fim de se poderem identificar as melhores práticas de gestão ambiental e, consequentemente, se porem em prática os melhores modelos.

Em 1996, os países membros da OCDE tinham já acordado a redução dos impactos negativos gerados por órgãos governamentais e organismos públicos (OECD, 1997). A própria OCDE, como organização supranacional, resolveu também adoptar os critérios ambientais ratificados pelos estados membros, incorporando-os nas suas actividades. Relativamente, por exemplo, à utilização de consumíveis esta organização instituiu medidas como uma redução do consumo total do papel de $11 \%$, um crescimento na percentagem de papel reciclado dentro do papel consumido, a substituição das máquinas copiadoras por outras com maior quantidade de peças passíveis de serem recicladas ou 
reutilizadas, assim como a redução do número de publicações em papel e a informatização crescente de documentos. No que concerne à adopção dos princípios pelos estados membros existe uma grande diversidade de comportamentos. Enquanto alguns se concentram na elaboração de disposições legais que visem a promoção da obrigatoriedade de adopção de certos critérios ambientais dentro dos organismos públicos, outros tentam fomentar a introdução de práticas ambientalistas de forma voluntária e isolada, organismo a organismo.

Em países como o Canadá e o Japão, algumas das medidas foram aplicadas de forma imediata, tendo os respectivos governos quantificado rigorosamente os objectivos a atingir em termos de gestão ambiental dentro dos serviços públicos. No que concerne, por exemplo, ao consumo de papel em organismos do estado, o Japão fixou em $0 \%$ o crescimento do volume total de consumo de papel para o período de 1996 a 2000 (Machado, 2002).

Apesar de todos os esforços já encetados, de acordo com o estudo efectuado por Machado (2002), no que concerne a gestão ambiental na administração pública, a maior parte dos países vive ainda aquilo que se pode designar como uma "cultura do desperdício". De entre as principais conclusões da pesquisa, avultam duas. Por um lado, assiste-se ainda nas administrações públicas a um comprometimento reduzido das altas direcções nas políticas e nas práticas ambientais de separação, recolha selectiva, reciclagem, ou reutilização, o que leva a que a repercussão dos princípios e das práticas ambientalistas não seja a desejável nos níveis intermédios e inferiores das hierarquias. Complementarmente, sem a adequada capacitação dos servidores do estado, o processo de uma melhor gestão ambiental dos recursos torna-se mais complicada.

De acordo com a supracitada autora, é hoje evidente que os governos e as administrações que adoptam comportamentos de redução de consumo de energia, reciclagem do papel utilizado, ou compra de produtos ecoeficientes ${ }^{2}$ colhem já vantagens passíveis de serem quantificadas (Machado, 2002). Deixa por isso de ser argumento a recusa de comportamentos ambientalistas com a desculpa de se tornarem mais dispendiosos para as organizações (públicas ou privadas).

No caso português, a OECD (2001) referia já em 1993 a absoluta necessidade de se elaborarem planos e investimentos de vulto, para a facilitação dos processos de gestão dos resíduos sólidos urbanos. Esta organização recomendava também o melhoramento dos mecanismos de inspecção e o desenvolvimento de um sistema de penalizações para os não cumpridores. Como principal objectivo colocou-se então a "implementação rápida de planos para a gestão dos resíduos com a determinação de uma hierarquia de responsabilidades no processo, que estivesse de acordo com a Agenda 21, e que permitisse monitorizar e implementar medidas, assim como recorrer a sistemas de avaliação" (OEDC, 2001: 88). Se é verdade que alguns passos foram dados a nível global no país, no que concerne à administração pública portuguesa que, por um lado, é uma enorme produtora de resíduos e que, por outro, deveria servir de exemplo de boas práticas ao resto do tecido social e empresarial nacional, pouco se modificou desde então.

No capítulo ambiental, a introdução de boas práticas no sector público deverá processar-se de forma sistematizada, apelando à tomada de consciência ambiental, sem

2 O produto ecoeficiente pode ser definido como aquele que, produzido de forma artesanal ou industrial, para uso pessoal, alimentar, residencial, comercial, agrícola ou industrial seja não poluente, não tóxico, reciclável, evidenciando benefícios para o meio ambiente e para a saúde. 
ignorar o peso da cultura napoleónica e weberiana que a administração pública veio adoptando desde cedo e que não sofreu alterações significativas nem no período que se seguiu à revolução de 1974 (Madureira, 2004).

$\mathrm{Na}$ gestão ambiental dentro dos organismos públicos, a via a seguir parece ser a da reforma gradualista. Para tal deve insistir-se na modificação de gestos diários rotineiros no quotidiano de dirigentes e funcionários. Desta forma, a médio e a longo prazo, será possível uma alteração atitudinal e comportamental que leve gradualmente à redução de consumos desnecessários e à implementação de práticas que, multiplicadas pelos organismos da administração pública, representem uma considerável redução de gastos, nomeadamente de energia, e de custos com materiais consumíveis.

\section{SEPARAÇÃO, RECOLHA SELECTIVA E RECICLAGEM DE MATERIAIS CONSUMÍVEIS E ELECTRÓNICOS NA ADMINISTRAÇÃO PÚBLICA POR- TUGUESA - LEGISLAÇÃO E PRÁTICAS}

Como já foi referido, também na administração pública portuguesa, uma parte considerável dos organismos existentes, dada a sua função de prestadores de serviços, utiliza materiais electrónicos e consumíveis diversos (em particular o papel) em abundância. Em Portugal, embora a Resolução do Conselho de Ministros no 2/93 de 7 de Janeiro tenha determinado a utilização de papel reciclado e a recolha selectiva de papel usado nos serviços da administração, decorridos quinze anos, esta não é uma prática corrente na maior parte dos organismos da administração pública portuguesa.

O Decreto-Lei $n^{\circ} 153 / 2001$ de 7 de Maio veio estabelecer regras, nomeadamente para que o equipamento informático de organismos da administração pública pudesse ser alienado a título gratuito no quadro dos processos de reequipamento e actualização do material informático dos mesmos.

Em 2002, o Decreto-Lei $n^{0}$ 20/2002 de 30 de Janeiro veio regulamentar a gestão dos resíduos de equipamentos eléctricos e electrónicos (REEE), quer no que diz respeito à recolha selectiva dos resíduos, quer ao respectivo armazenamento, transporte e tratamento. Mais tarde, obedecendo ao disposto na Directiva n. ${ }^{\circ}$ 2002/95/CE do Parlamento Europeu e do Conselho, de 27 de Janeiro de 2003, e na Directiva n. ${ }^{\circ}$ 2002/96/CE do Parlamento Europeu e do Conselho, de 27 de Janeiro de 2003, alterada pela Directiva n. ${ }^{\circ}$ 2003/108/CE do Parlamento Europeu e do Conselho, de 8 de Dezembro de 2003, o Decreto-Lei n. ${ }^{\circ}$ 230/2004 de 10 de Dezembro veio estabelecer um regime jurídico para a gestão de resíduos de equipamentos eléctricos e electrónicos (REEE) tendo por objectivos prevenir a sua produção, promover a reutilização, a reciclagem e outras formas de valorização, de forma a reduzir a quantidade e o carácter nocivo de resíduos a eliminar, contribuindo para melhorar o comportamento ambiental de todos os operadores envolvidos no ciclo de vida destes equipamentos. Posteriormente, o Despacho Conjunto n. ${ }^{\circ}$ 353/2006 de 27 de Abril veio conferir o licenciamento de uma entidade gestora do sistema integrado de gestão de resíduos de equipamentos eléctricos e electrónicos (REEE), a ERP Portugal, e o Despacho Conjunto n. ${ }^{\text {o } 354 / 2006}$ veio conferir o licenciamento de uma outra entidade gestora do sistema integrado de gestão de resíduos de equipamentos eléctricos e electrónicos (REEE), a AMB3E, Associação Portuguesa de Gestão de Resíduos de Equipamentos Eléctricos e Electrónicos.

Por outro lado, o Despacho n. ${ }^{\circ}$ 454/2006 de 9 de Janeiro, que aprovou o Plano de Intervenção de Resíduos Sólidos Urbanos e Equiparados (PIRSUE), estabelece na medida 
9 do seu eixo 2, a obrigatoriedade de recolha selectiva de resíduos na administração, fundamentando esta necessidade no enquadramento estratégico nacional e comunitário para a gestão dos resíduos.

Já em 2007, a Resolução do Conselho de Ministros n. ${ }^{\circ}$ 109/2007 de 20 de Agosto criou a Estratégia Nacional de Desenvolvimento Sustentável, que está na base da promoção de um sistema de compras públicas, a implementar no período de 2008 a 2010, que pretende incorporar, na contratação pública, critérios de política ambiental e de sustentabilidade, promovendo os denominados "mercados verdes" e visando reforçar a disseminação de boas práticas dentro e fora da administração pública.

Apesar de ser evidente uma evolução no que concerne à legislação, as práticas de gestão de separação, recolha selectiva e reciclagem de materiais electrónicos e consumíveis (papel, tinteiros e toners em especial) na administração pública portuguesa são ainda pouco conhecidas, não tendo ainda dado nenhum sinal de mudança particularmente significativa em termos culturais e comportamentais, no que concerne a estas matérias. Embora a literatura sobre esta temática não seja abundante no nosso país, torna-se evidente, em visitas aleatórias aos serviços, que não existe nem uma política consolidada de separação e de recolha selectiva, nem um modelo de gestão ambiental para os organismos públicos.

\section{METODOLOGIA E RESULTADOS}

Para se responder ao objectivo do estudo, já enunciado na introdução, foram utilizados dados recolhidos por dois instrumentos de recolha de informação distintos: (i) um inquérito dirigido aos membros do clube net@ina (trata-se de uma comunidade virtual de funcionários públicos, formandos do INA, IP ou simplesmente interessados nas actividades deste Instituto), através de questionário electrónico disponível on-line; um inquérito aos dirigentes máximos de todos os organismos públicos da administração pública central, através de questionário enviado via postal com um envelope RSF para facilitar as respostas. Ambos os questionários estiveram disponíveis para resposta entre 12 de Fevereiro e 14 de Março de 2008.

Os dois questionários apresentam algumas perguntas comuns e outras distintas. Esta opção sustenta-se no facto de a população dirigente (ou das chefias, ou funcionários indicados pelos dirigentes para preencherem o questionário) dever não só estar a par das práticas de separação e recolha selectiva de resíduos nos seus organismos mas até participar nas estratégias para que estas aconteçam.

\section{Universo do estudo e amostras}

O primeiro universo de estudo é composto pelos membros do clube net@ina.pt, contando com 15.015 funcionários públicos, tendo sido obtida uma amostra de 858 respostas validadas.

O segundo universo de estudo é composto pelos dirigentes máximos de todos os organismos da administração pública central (671 efectivos), tendo sido validada uma amostra de 225 respostas.

Depois de tratados os dados recolhidos através dos questionários, pretendemos dar a conhecer os resultados obtidos no estudo e tornar pública a situação na administração pública central no que concerne às práticas de reutilização, separação, recolha selectiva e reciclagem de resíduos. 


\section{Resultados do inquérito aos membros do clube net@ina.pt}

A maioria dos inquiridos $(92,4 \%)$ afirma separar os resíduos em casa, mas no local de trabalho, essa percentagem desce para $69,1 \%$.

Quanto às motivações principais que levam os inquiridos a separarem os resíduos em casa (quadro I), prevalece a consciência da importância que a separação dos resíduos tem para que sejam reciclados. De forma minoritária, são ainda indicadas as campanhas de sensibilização e a pressão exercida pelos filhos. Da leitura destes resultados pode admitir-se que a maioria dos inquiridos com hábito de separação é motivada pelo facto de estar informada em relação a problemas ambientais e à importância da separação para recolha selectiva dos resíduos e consequente reciclagem.

Quadro I - Principal motivo para a separação de resíduos em casa.

Table I - Main motive for waste separation at home.

\begin{tabular}{lrr}
\hline & N & $\mathbf{\%}$ \\
\hline A pressão exercida pelos filhos & 26 & 3,3 \\
A pressão para a separação de resíduos sólidos urbanos ser bem vista socialmente & 3 & 0,4 \\
A consciência da importância da separação dos resíduos para a reciclagem & 712 & 90,0 \\
Campanhas de sensibilização & 35 & 4,4 \\
Outro & 15 & 1,9 \\
\hline Total & 791 & 100,0 \\
\hline
\end{tabular}

No que concerne ao principal motivo para o exercício de uma prática de separação de resíduos no local de trabalho (quadro II), a consciência de cada pessoa revela-se determinante, havendo também um significativo número de inquiridos que refere a influência de directivas hierárquicas.

Quadro II - Principal motivo para a separação de resíduos no local de trabalho.

Table II - Main motive for waste separation in the workplace.

\begin{tabular}{lrr}
\hline & $\mathbf{N}$ & $\mathbf{\%}$ \\
\hline A consciência de cada pessoa & 665 & 77,5 \\
Uma directiva do dirigente máximo do organismo & 119 & 13,9 \\
Uma obrigação legal & 47 & 5,5 \\
Uma política do Ministério & 27 & 3,1 \\
\hline Total & 858 & 100,0 \\
\hline
\end{tabular}

Quando inquiridos em relação à existência de articulação entre todos os serviços do organismo relativamente à separação de resíduos, a maioria $(51,3 \%)$ afirma não existir e $21,1 \%$ refere não ter qualquer conhecimento sobre esta matéria. De facto, apenas cerca de um quarto $(27,6 \%)$ admite a existência de articulação entre os serviços no que diz respeito à separação de resíduos dentro do organismo. 
Em relação à existência de equipamentos para separação de resíduos, os resultados apontam para o facto de cerca de metade da amostra admitir a sua existência no organismo $(53,4 \%)$ e dentro dos gabinetes $(47,3 \%)$. Contudo, a figura 1 mostra que os tipos de resíduos separados dos restantes têm configurações diferentes, consoante se refiram os recipientes dentro dos gabinetes ou fora deles (no organismo). Nos dois casos, o papel é o mais referido. No caso dos gabinetes, aparecem em segundo lugar os resíduos orgânicos, seguidos das embalagens e das pilhas. Fora dos gabinetes, as embalagens são o segundo tipo de resíduo referido, seguidas do vidro, dos resíduos orgânicos e das pilhas. As lâmpadas, os tinteiros e toners são os tipos de resíduos que menos frequentemente foram referidos como tendo recipientes apropriados.

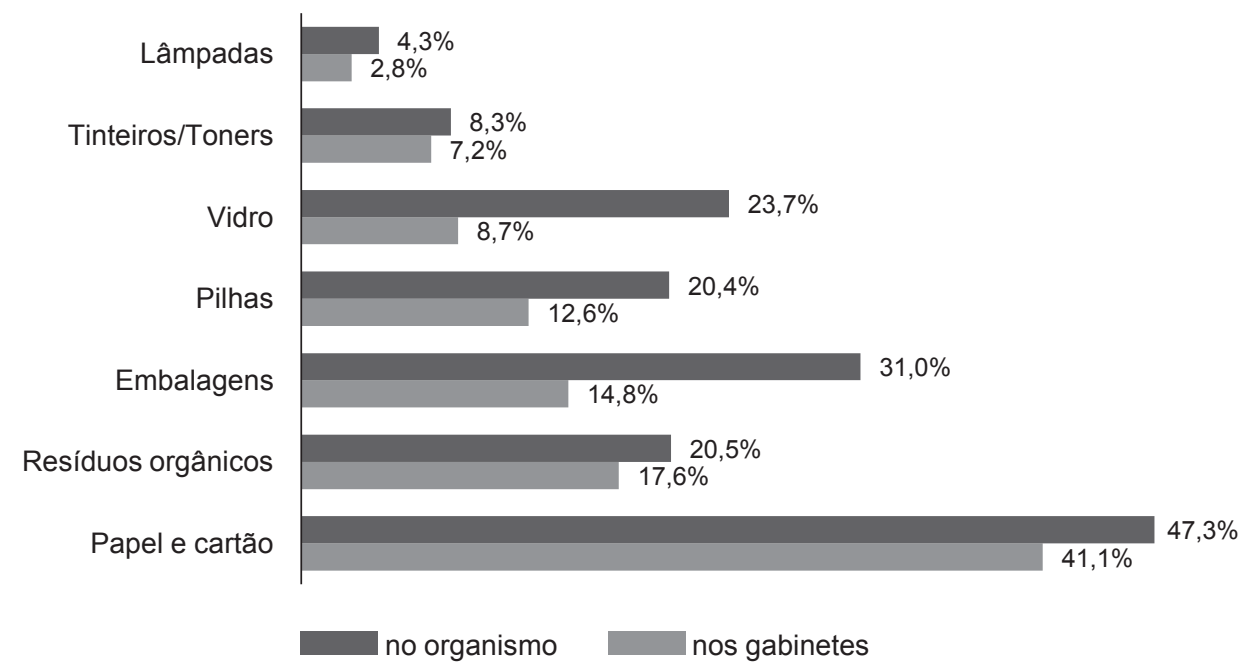

Fig. 1 - Existência de recipientes para separar resíduos (por tipo).

Fig. 1 -Presence of containers for the purpose of waste separation (by type).

No que diz respeito à utilização de papel até ao limite, nomeadamente através da impressão em frente e verso e da reutilização de folhas pré-impressas de um dos lados para rascunho, percebeu-se que a maioria dos inquiridos revela ter boas práticas, já que $33,1 \%$ da amostra admite fazer "sempre" este tipo de utilização e $43,1 \%$ o faz "frequentemente". Em sentido oposto, apenas 1,6\% referiu "nunca" utilizar o papel até ao seu limite. Nesta amostra de inquiridos verifica-se, pois, que a maioria tem comportamentos de reutilização frequentes e reiterados.

De acordo com os dados constantes na figura 2, mais de $70 \%$ dos funcionários respondentes admitem que o envolvimento dos dirigentes na mudança comportamental dos funcionários, no que concerne aos hábitos de separação de resíduos no local de trabalho, é "pouco" ou "nenhum". Também no que respeita ao grau de sensibilidade dos dirigentes relativamente à importância da separação e recolha selectiva de resíduos no geral, a maioria dos inquiridos considera que é "pouco" ou "nenhum" (57,3\% no total). 

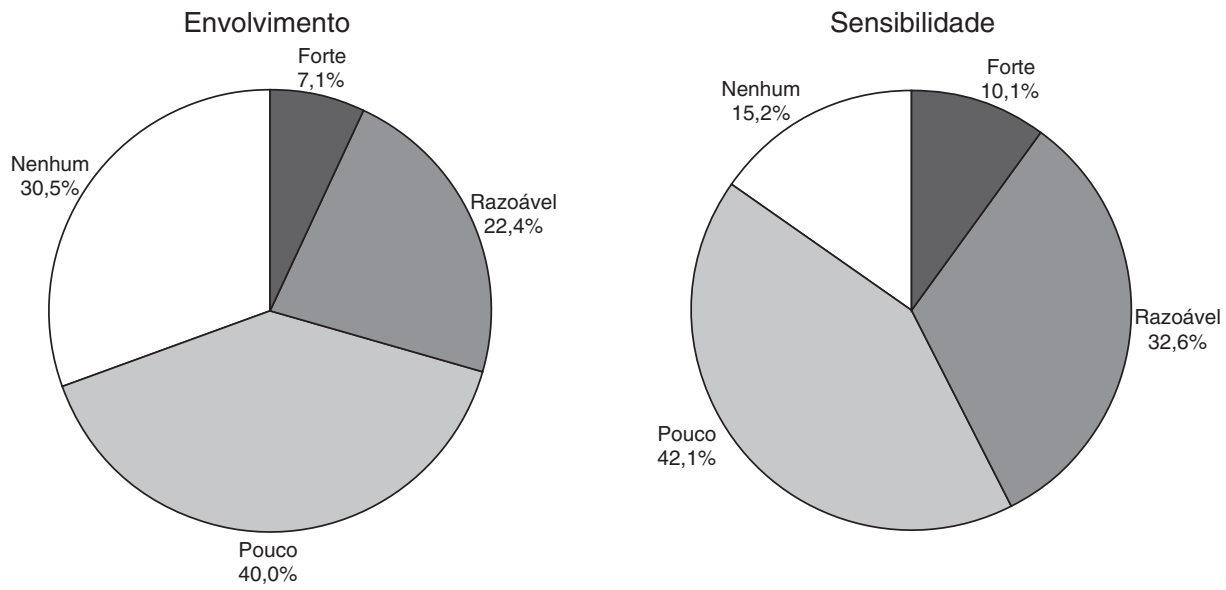

Fig. 2 - Graus de envolvimento dos dirigentes na mudança comportamental dos funcionários e de sensibilidade quanto à importância da separação e recolha selectiva de resíduos.

Fig. 2 -Degree of involvement of the managers in the process of behavioural change by their subordinates and level of awareness with regard to the importance of selective waste separation and collection.

Os inquiridos foram chamados a pronunciar-se sobre a importância de se fazerem acções de formação para a mudança de comportamentos em matéria de separação de resíduos no posto de trabalho. A esmagadora maioria considera a formação comportamental "muito importante" $(60,7 \%)$ ou "relativamente importante" $(33,9 \%)$, e apenas 5,4\% atribui "pouca" ou "nenhuma" importância a esta matéria. Quanto aos destinatários preferenciais da formação, os respondentes referem que os dirigentes intermédios $(81,6 \%)$ e de topo $(68,2 \%)$ deverão ser os principais destinatários destas acções, tendo os técnicos superiores sido referidos em $55 \%$ dos casos e outros técnicos em 58,3\%.

O questionário incluía ainda uma questão aberta sobre a opinião dos inquiridos quanto à existência de um modelo de gestão ambiental comum a toda a administração pública. De acordo com os resultados apurados, a maioria dos inquiridos $(85,9 \%)$ considera que esse modelo deve existir. Pelo contrário, 6,1\% considera que não deve existir um modelo de gestão ambiental comum, tendo $3,1 \%$ revelado indecisão.

De entre as opiniões referidas que fundamentaram concordância com a existência de um modelo de gestão ambiental comum a toda a administração pública, salientam-se a necessidade e a importância da uniformização de normas, regras e procedimentos para a separação e recolha selectiva de resíduos, bem como a maior facilidade e eficácia de implementação de políticas comuns. Foram ainda referidos argumentos como a importância da articulação entre os serviços públicos e os prestadores de serviços de recolha selectiva de resíduos, o maior rigor por parte dos organismos públicos, o verdadeiro envolvimento da classe dirigente, e o papel da administração pública na difusão de boas práticas, contribuindo para a sensibilização dos funcionários, para a realização efectiva da separação de materiais nos seus locais de trabalho e na sua vida privada.

Por outro lado, foi referido que a separação e recolha selectiva de resíduos deveria fazer parte dos objectivos das organizações e que a implementação de um modelo comum 
potenciaria a criação de uma cultura ambiental comum a toda a administração pública e ao mesmo tempo, permitiria criar modelos mais eficazes, facilitando a troca de informações e experiências entre organismos. São sugeridas soluções como a inclusão de objectivos de reciclagem na avaliação do desempenho ou a existência de um Manual de Princípios Básicos e de Boas Práticas, bem como a formação, a envolvência, a informação e o desenvolvimento de meios operacionais.

As fundamentações das respostas dos respondentes que acham que não deve ser aplicado um modelo comum a toda a administração pública, recaem essencialmente nos argumentos de que a imposição legal tende a ser contraproducente e que as práticas actuais são suficientes; que a adopção de medidas legislativas sobrecarregaria e tornaria ainda mais complexo o funcionamento dos serviços; que os organismos têm especificidades que não permitem a uniformização de processos; e que a separação de resíduos deve assentar fundamentalmente no aspecto comportamental da consciência individual. Apesar de não concordarem com o modelo comum, alguns consideram que deveria ser obrigatória a existência de pontos comuns e de recipientes para a separação de resíduos em todos os organismos.

Finalmente, aqueles que colocam algumas reservas a um modelo comum, referem que deve existir um modelo estratégico mas flexível, passível de adaptação a situações específicas. Consideram que deve haver mais regulamentação e equipamento, contribuindo assim para uma maior sensibilização e envolvimento dos funcionários.

\section{Resultados do inquérito a dirigentes}

De acordo com as respostas da amostra de dirigentes, em mais de 2/3 dos organismos inquiridos, está instituída uma prática de separação de resíduos, ou no organismo como um todo $(35,5 \%)$ ou na maioria dos seus serviços $(33,2 \%)$. Em 12,4\% dos casos, é admitido que nenhum serviço leva a cabo esta prática, e em 18,9\% apenas um número reduzido de serviços o faz. Em quase metade dos organismos $(49,7 \%)$, a separação de resíduos decorre de decisões avulsas e só em $32,8 \%$ de directivas do dirigente máximo.

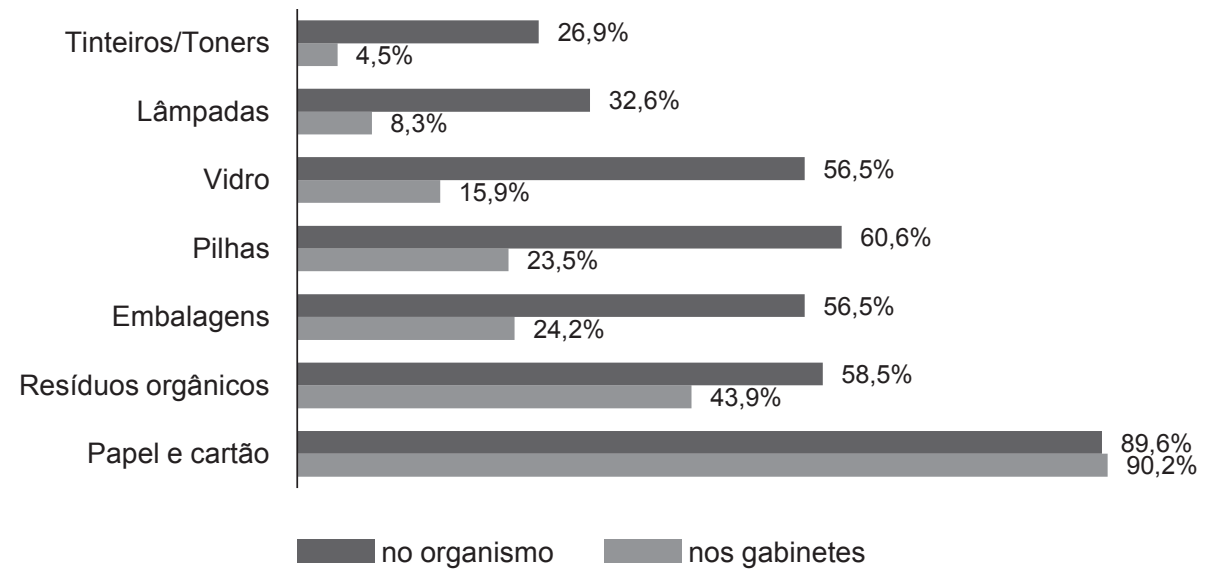

Fig. 3 - Existência de recipientes para separar resíduos (por tipo).

Fig. 3 - Presence of dedicated containers for the purpose of waste separation (by type). 
Quanto à existência de equipamentos para separação de resíduos, os resultados apontam para o facto de a maioria da amostra admitir a sua existência no organismo $(85,8 \%)$ e dentro dos gabinetes $(58,5 \%)$. Por outro lado, a figura 3 evidencia diferenças quanto ao tipo de resíduos separados, dentro dos gabinetes ou fora deles. Nos dois casos, o papel é o mais referido. Dentro dos gabinetes, os resíduos orgânicos aparecem na segunda posição, seguidos das embalagens e das pilhas. Fora dos gabinetes, as pilhas são o segundo tipo de resíduo referido, seguidas dos resíduos orgânicos, das embalagens e do vidro. A maioria dos organismos (95\%) admite ainda fazer separação e recolha selectiva de tinteiros e toners para posterior reciclagem.

De acordo com os dirigentes, a utilização de papel reciclado é uma prática minoritária nos organismos abrangidos pelo inquérito, já que cerca de $2 / 3$ da amostra não recorre a esta solução $(33,2 \%)$ ou apenas o faz pontualmente $(32,3 \%)$. De facto, apenas $2,2 \%$ afirma utilizar sempre papel reciclado, $9 \%$ fá-lo frequentemente e $23,3 \%$ às vezes.

No que concerne o material informático desactualizado, a maioria $(53,8 \%)$ tem acordos com operadores licenciados para abate do mesmo, havendo igualmente situações de reaproveitamento interno $(46,2 \%)$ e de doação a instituições terceiras $(41,2 \%)$. No entanto, pouco mais de metade dos organismos $(55,5 \%)$ afirma ter conhecimento de entidades gestoras responsáveis pelo Sistema Integrado de Gestão de Resíduos de Equipamentos Eléctricos e Electrónicos (REEE). Apenas cerca de um quarto dos inquiridos $(24,7 \%)$ faz entregas deste tipo de resíduo a entidades daquele sistema. Quanto ao Sistema Integrado de Registo Electrónico de Resíduos (SIRER), apenas 45,5\% dos organismos tem conhecimento da sua existência e menos de um terço $(28,9 \%)$ leva a cabo o seu preenchimento.

Embora $40 \%$ dos organismos afirmem ter um contrato, acordo ou protocolo para a recolha de resíduos, estes não constituem um quadro de articulação integrada com um agente em particular. De facto, a maioria das situações resulta de soluções pontuais e avulsas.
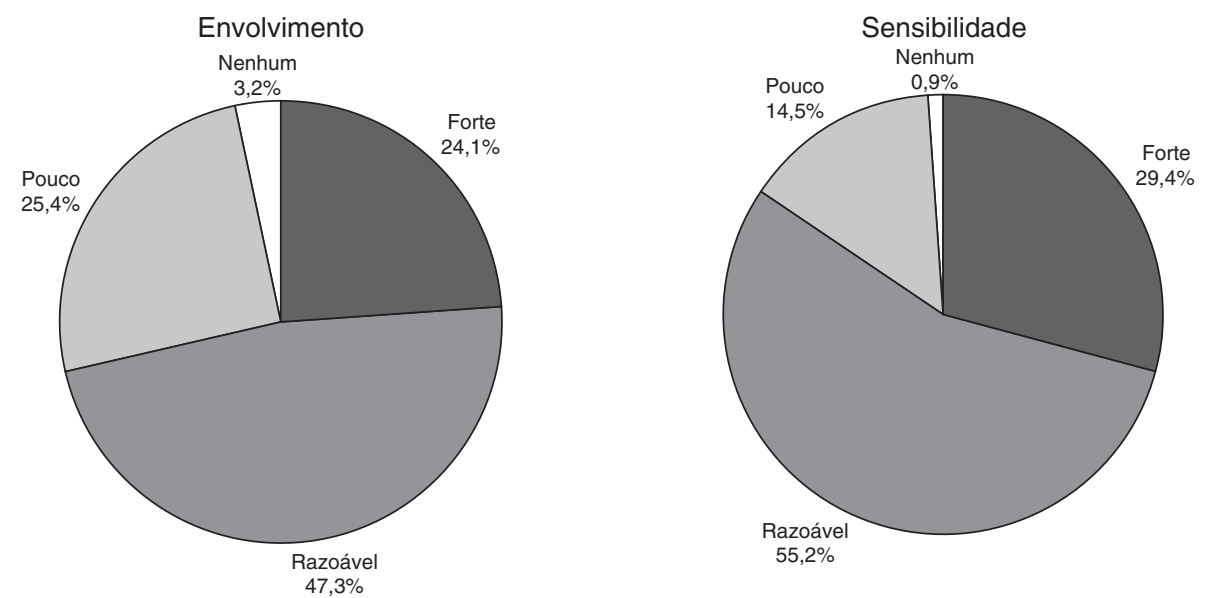

Fig. 4 - Graus de envolvimento dos dirigentes na mudança comportamental dos funcionários e de sensibilidade quanto à importância da separação e recolha selectiva de resíduos.

Fig. 4 -Degree of involvement of the managers in the process of behavioural change by their subordinates and level of awareness with regard to the importance of selective waste separation and collection. 
De acordo com a figura 4 , a maioria dos dirigentes inquiridos $(71,4 \%)$ afirma que o seu envolvimento na mudança comportamental dos funcionários em relação a hábitos de separação de resíduos é "absoluto" ou "razoável" e, em 84,6\% dos casos, é reconhecido um grau de sensibilidade dos dirigentes relativamente à importância da separação e recolha selectiva "absoluto" ou "razoável".

Por outro lado, de acordo com a opinião dos dirigentes, a formação para a mudança de comportamentos em matéria de separação de resíduos é considerada "muito" (64,7\%) ou "algo" importante (32,6\%), havendo apenas uma minoria de $2,7 \%$ que considera este tipo de acção pouco importante. Os dirigentes intermédios são mais frequentemente referidos como destinatários preferenciais desta formação $(84,9 \%)$, seguidos de outros técnicos $(72,5 \%)$, técnicos superiores $(69,3 \%)$ e dirigentes de topo $(61,5 \%)$

Finalmente, quanto a um modelo de gestão ambiental comum a toda a administração pública, a maioria dos organismos $(80,9 \%)$ concorda com a sua existência, e apenas $5,3 \%$ afirma não concordar. Os argumentos avançados a favor desta ideia incluem a definição e implementação de melhores práticas, agilização e uniformidade de procedimentos, o eventual reaproveitamento noutras instituições. Foram também realçados aspectos como a integração de objectivos ambientais na gestão dos organismos, a importância da divulgação de boas práticas, do investimento em formação e da motivação nos serviços públicos.

Em sentido contrário, aqueles que se manifestaram contra a existência de tal modelo comum defendem que deve ser cada organismo a tomar as suas próprias opções, devendo antes apostar na informação e formação dos trabalhadores e na implementação de regras básicas.

\section{Discussão}

Depois de analisados os resultados torna-se evidente um desajuste, quase uma contradição, relativamente a algumas respostas fornecidas pelas duas amostras.

No que concerne à "existência de recipientes para separar resíduos dentro dos gabinetes (por tipo de resíduos)", as respostas dos dirigentes são francamente mais encorajadores do que as do clube net@ina. Enquanto 90,2\% dos primeiros referem poder proceder à separação de papel e cartão dentro dos próprios gabinetes, apenas $41,1 \%$ dos sujeitos respondentes do clube net@ina admitem poder fazer o mesmo. Ainda que não tão acentuada, a diferença de respostas entre amostras é também encontrada relativamente à separação de todos os outros tipos de resíduos. Esta discrepância de valores é também notada na resposta à questão que visa perceber se "existem pontos/recipientes para separação de resíduos dentro do organismo". Enquanto apenas $53,4 \%$ dos inquiridos do clube net@ina reconhece a existência destes recipientes, $85,8 \%$ dos dirigentes confirmam que estes existem disponíveis nos organismos onde exercem as suas funções.

Por outro lado, existe uma percentagem consideravelmente maior de dirigentes a responderem que o principal motivo para o exercício de uma prática de separação de resíduos no local de trabalho é a existência de "uma directiva do dirigente máximo do organismo" nesse sentido $(32,8 \%)$ do que de respondentes da amostra do clube net@ina (13,9\%).

Ainda de realçar que, enquanto mais de $71 \%$ da amostra dos dirigentes acha que o envolvimento dos dirigentes na mudança comportamental dos funcionários, no que concerne aos hábitos de separação de resíduos no trabalho, é "razoável" ou mesmo 
"absoluta", 70,5\% dos respondentes da amostra do clube net@ina admite que este grau de envolvimento não passa de "fraco" ou mesmo "nulo".

Os dois grupos parecem apenas concordar que é "muito importante" ou pelo menos "importante" que se desenvolvam acções de formação para a alteração de comportamentos em matéria de separação de resíduos no posto de trabalho, concordando também que deverão ser os dirigentes intermédios os principais destinatários destas acções. Esta coincidência de propostas pode perceber-se na medida em que são efectivamente os dirigentes intermédios aqueles que convivem diariamente com os funcionários podendo influenciar de forma mais directa os modelos culturais, atitudinais e comportamentais dos mesmos, ou seja, contribuindo para um descongelamento, uma mudança e um recongelamento (confirmação dessa mudança) das formas de acção dos funcionários no seu local de trabalho (Lewin, 1965, Schein, 1987).

Por fim, importa salientar que, em quase todas as comparações de resultados entre as duas amostras, aparece como evidente um optimismo nas respostas fornecidas pela amostra dos dirigentes, sobretudo quando comparadas com as dos respondentes membros do clube net@ina. Tal facto não será de estranhar. Tratar-se-á porventura de um sentimento de desejabilidade social (Madureira, 2004) partilhado por chefias e dirigentes que, por se sentirem responsáveis pelo correcto funcionamento dos organismos, tendem a desejar que, do ponto de vista da gestão ambiental, exista já um conjunto de boas práticas definitivamente implementadas. Ou seja, a expectativa, em alguns casos, poderse-á ter substituído à realidade no momento das respostas, exagerando assim a percentagem de ocorrência de boas práticas ambientais no local de trabalho.

\section{CONCLUSÕES E RECOMENDAÇÕES}

A presente investigação propôs-se fazer o diagnóstico do estádio de desenvolvimento dos processos de separação e recolha selectiva de resíduos nos organismos da administração pública central portuguesa.

As respostas dadas pela amostra do clube net@ina indicaram que existe um hábito de separação mais pronunciado nos lares dos funcionários do que nos seus locais de trabalho (organismos da administração pública central); a maioria dos funcionários não tem ideia de como se articulam entre serviços as práticas de separação e de recolha; só em cerca de metade dos organismos existem pontos de separação (sejam estes dentro ou fora dos gabinetes de trabalho); o tipo de resíduos ao qual se destinam mais pontos de separação é o papel; na maioria dos casos, o papel já é utilizado até ao limite; a consciência individual é o principal motivo para o exercício de uma prática de separação de resíduos no local de trabalho; o envolvimento dos dirigentes na mudança de comportamentos dos funcionários em matéria de separação é muito fraco; a formação profissional nesta matéria afigura-se como fundamental, designadamente para o grupo profissional dos dirigentes intermédios (naturalmente mais próximos dos funcionários e das suas rotinas).

Relativamente às respostas dadas pelos dirigentes, elas apresentam algumas semelhanças (que não merecem ser repetidas) mas também pontos de desacordo e de novidade (visto que os instrumentos de recolha de informação eram, também eles, diferentes) que importam ser referidos nesta fase do trabalho. Contrariando os números apresentados pelas respostas do clube net@ina, os dirigentes afiançam que: em cerca de 86\% dos organismos existem recipientes para separação de resíduos dentro do organismo; a fre- 
quência de utilização de papel reciclado é muito baixa; quase sempre se faz uma separação e recolha selectiva de toners e tinteiros, tendo em vista a reciclagem dos mesmos; sabem, na sua maioria, da existência de entidades gestoras responsáveis pelo Sistema Integrado de Gestão de Resíduos de Equipamentos Eléctricos e Electrónicos (REEE) embora só uma minoria proceda a uma entrega dos mesmos a estas entidades; apenas menos de metade dos organismos tem conhecimento da existência do Sistema Integrado de Registo Electrónico de Resíduos (SIRER) tendo pouco mais de 1/4 o hábito de o preencher; o grau de sensibilidade relativamente à separação e recolha e o envolvimento dos dirigentes na mudança de comportamentos dos funcionários nesta matéria é forte.

Há quase duas décadas que autores como Folz \& Hazlett (1991) vêm afirmando que o sucesso dos programas de separação, de recolha selectiva e de reciclagem depende essencialmente das políticas para o ambiente, da forma como são escolhidas, seleccionadas e implementadas por governos e administrações. Contudo, no caso da administração pública central portuguesa, podemos concluir que os resultados deste estudo nos permitem afirmar que não existe ainda um hábito solidamente enraizado e sistematizado de separação e recolha selectiva de resíduos. Vivemos ainda, pelo menos parcialmente, uma "cultura de desperdício" (Machado, 2002). Como pudemos observar ao longo da pesquisa, para isso têm contribuído vários factores. Em face dos resultados podemos concluir que existe uma ausência de gestão ambiental na maioria dos organismos respondentes ao inquérito ${ }^{3}$.

Assim como já vai acontecendo com outros eixos de importância vital para o desenvolvimento sustentável, como é o caso da igualdade de género e/ou a cidadania inclusiva, pensamos que, em vez de se constituir como política pública em si mesma, a gestão ambiental deveria ganhar gradualmente um carácter de transversalidade e de afirmação na sociedade portuguesa, de modo a poder vir a ser monitorizada (OECD, 2001). Só a observação e a prática continuadas de rotinas ambientalistas poderão levar a que a separação e a recolha selectiva se transformem em actos naturais, seja no contexto familiar ou no laboral, no sector público ou no privado. Para que tal possa acontecer, torna-se fundamental que os dirigentes se envolvam neste processo de descongelamento (descristalização) de velhos hábitos assim como na aprendizagem, partilhada com os funcionários, de novos comportamentos de forma consciente (Lewin, 1965; Schein, 1987).

Com efeito, não bastam leis nem directivas nos organismos públicos. A importância de novos comportamentos mais ecológicos tem que ser percepcionada como necessária e incontornável pelos dirigentes. Só assim a difusão de novas práticas para todos os funcionários será possível, pelo menos de forma sistematizada. Se assim não for, continuaremos a assistir a comportamentos mais ou menos generalizados ou isolados de funcionários mais conscienciosos, o que não permite que os resíduos dos Organismos sejam separados, recolhidos, reutilizados e geridos da melhor forma.

Para que uma gestão ambiental possa vir a tornar-se realidade a aposta deverá desdobrar-se em nova legislação para os organismos públicos, formação e difusão de novas atitudes e comportamentos assim como a instituição de processos de benchmarking com o fim de se poderem identificar as melhores práticas de gestão ambiental e, consequentemente, se porem em prática os melhores modelos para o efeito (Folz, 2004).

3 Gestão ambiental: conjunto de processos articulados para solucionar problemas da área ambiental de forma sistematizada 


\section{BIBLIOGRAFIA}

Aranha M L A, Martins M H P (1993) Temas de Filosofia. Editora Moderna, São Paulo.

Folz D H (2004) Service quality and benchmarking the performance of municipal services. Public Administration Review, 64(2): 209-220.

Folz D H, Hazlett J M (1991) Public participation and recycling performance: explaining program success. Public Administration Review, 51(6): 526-532.

Lewin K (1965) Teoria de campo em ciência social. Livraria Pioneira Editora, São Paulo.

Machado J G (2002) Gestão ambiental na administração pública: a mudança dos padrões de consumo "Começa em Casa". Dissertação de Mestrado, Universidade de Brasília, Centro de Desenvolvimento Sustentável.

Madureira C (2004) A formação comportamental no contexto da reforma da Administração Pública. Edições INA, Oeiras.

Marcuse H (2001) Une nouvelle ordre. Manière de Voir (Sociétés sous Contrôle), 56.

OECD (2001) Environmental Performance Reviews - Portugal. Paris.

OECD (1999) Report by the Environmental Policy Committee on Implementation of the 1996 Recomendation on Improving the Environmental Performance of Government. C(99)33/FINAL, 1999.

OECD (1997) Programme on sustainable consumption and production. Workshop on Improving the environmental Performance of Government. Paris, October, OECD/GD(97)124.

Portilho F (2005) Sustentabilidade ambiental, consumo e cidadania. São Paulo.

Ramonet I (2004) O novo rosto do mundo. Campo da Comunicação, Lisboa.

Schein E (1987) Process consultation. Reading, Addison-Wesley, 2.

Tchobanoglous G, Theisen H, Vigil S A (1993) Integrated solid waste management - engineering principles and management issues. McGraw-Hill International Editions, Singapore.

\section{BIBLIOGRAFIA JURÍDICA}

- Lei n. ${ }^{\circ}$ 11/1987, de 7 de Abril - Lei de Bases do Ambiente.

- Resolução do Conselho de Ministros 2/1993, de 7 de Janeiro

- Decreto-Lei n. ${ }^{\circ}$ 153/2001, de 7 de Maio

- Decreto-Lei n. ${ }^{o}$ 20/2002 de 30 de Janeiro

- Directiva 2003/108/CE do Parlamento Europeu e do Conselho, de 8 de Dezembro de 2003,

- Decreto-Lei n. ${ }^{\circ}$ 230/2004 de 10 de Dezembro

- Despacho n. ${ }^{\circ}$ 454/2006, de 9 de Janeiro

- Despacho Conjunto n. ${ }^{o}$ 353/2006

- Resolução do Conselho de Ministros 109/2007 